\title{
Atuação do Ministério Público do Trabalho relacionada à saúde do trabalhador e meio ambiente de trabalho na Justiça do Trabalho (2000- 2014)
}

Performance of the Brazilian Public Prosecution Department related to workers' health and working environment in the Labor Court (2000-2014)

Actuación del Ministerio Público del Trabajo respecto a la salud laboral y el medio ambiente de trabajo en la Justicia de Trabajo (2000-2014)

Caroline da Cunha Diniz ${ }^{1}$ Luiz Carlos Pelizari Romero ${ }^{2}$

RESUMO. Introdução: o estudo analisa as sentenças proferidas nas Ações Civis Públicas propostas pelo Ministério Público do Trabalho nas Varas Trabalhistas da 10 Região (Distrito Federal e Tocantins), relacionadas à saúde do trabalhador e meio ambiente de trabalho, no período de 2000 a 2014, verificando suas características e a repercussão da Emenda Constitucional no 45, de 2004. Metodologia: tratou-se de pesquisa quantitativa e qualitativa, por meio de banco de dados secundário, do sítio do Tribunal Regional do Trabalho da 10 ${ }^{\underline{a}}$ Região. Resultados: das 633 sentenças proferidas, 70 tratam de saúde do trabalhador e ambiente de trabalho, notando-se intensificação da atuação do Ministério Público do Trabalho após a Reforma do Judiciário. Quanto à atividade econômica da empresa demandada, predominou a construção civil e atividades relacionadas a ela; quanto ao objeto, houve predomínio de inobservância dos limites legais para duração da jornada de trabalho. Quando à norma jurídica, foram invocadas com maior frequência os artigos da Constituição e a norma relacionada com equipamento de proteção individual. Verificou-se elevada frequência de deferimento da antecipação dos efeitos da tutela e julgamento com procedência da ação. Conclusão: apesar dessa atuação, os índices de acidentes de trabalho e doenças ocupacionais têm progredido tanto em nível regional quanto nacional, exigindo coalizão do poder público em prol dessa questão de saúde pública.

Palavras-chave: Saúde do Trabalhador. Ambiente de Trabalho. Tutela Inibitória. Justiça do Trabalho.

ABSTRACT. Introduction: the research entails the judgements in the Public Civil Action proposed by the Public Labor Ministry for the Regional Labor Court, $10^{\text {th }}$ Region, regarding workers' health as well as working environment, within the yeas of 2000 up to 2014, analyzing their particularities and repercussion of the Constitutional Amendment \#45/2004. Methodology: it refers to both quantitative and qualitative aspects, through data base, on the local Labour Court website. Results: Out of the 633 delivered sentences, 70 broach workers' health and working environment, allowing ourselves to

\footnotetext{
${ }^{1}$ Médica. Especialista em Direito Sanitário, Medicina do Trabalho, Medicina Legal e Perícia Médica. Secretaria de Gestão Administrativa e Desburocratização, Subsecretaria de Saúde. Brasília, DF, Brasil. E-mail: dra.carolinediniz@gmail.com

${ }^{2}$ Médico. Especialista em Direito Sanitário e Saúde Pública pela Fiocruz.
} 
evincing the escalating action of the Public Labor Ministry, following the Judiciary reform. As for the economic activity of the prosecuted company, construction field is prevailing as well as related activities; as for the object, inobservances of the legal limits regarding the workdays length is rife. Approaching forensic norms, there have been most frequently evoked the constitutional articles and also the individual protection equipment related norm. There has also been verified the high incidence of tutorage effects anticipation grants and favorably judged lawsuits. Conclusion: despite that action, the levels of labour accidents and occupational illnesses has increased both regionally and nationally, demanding public power coalition in favor of this public health matter.

Keywords: Occupational Health, Working Environment, Inhibiting tutorage, Labor Justice

RESUMEN. Introducción: son analizadas las sentencias emitidas en acciones civiles publicas propuestas por el Ministerio Público del Trabajo para las secciones de trabajo de la décima región d la Justicia Federal de Brasil (Distrito Federal e Provincia de Tocantins), con respecto a la salud de los trabajadores y el entorno de trabajo, desde de 2000 hasta 2014, el análisis de sus particularidades y la repercusión de la Enmienda Constitucional no 45/2004. Metodología: se refiere tanto a los aspectos cuantitativos y cualitativos, a través de la base de datos, en el sitio web local de Tribunal Regional del Trabajo. Resultados: de las 633 sentencias entregadas, 70 se refiere la salud de los trabajadores y el entorno de trabajo, evidenciando la acción creciente del Ministerio Público del Trabajo, después de la reforma judicial. En cuanto a la actividad económica de la empresa procesada, predomina la construcción civil y atividades relacionadas; como para el objeto, inobservancia de los límites legales en cuanto a la duración de la jornada laboral es predominante. En cuanto a las normas jurídicas, se han registrado más frecuentemente evocados los artículos constitucionales y la norma relacionada al equipo de protección individual. También se ha comprobado la alta incidencia de diferimiento del amparo y de demandas favorablemente juzgadas. Conclusión: pesar de esta actuación del Ministerio Publico, los niveles de accidentes de trabajo y enfermedades profesionales se han incrementado tanto a nivel regional como nacional, exigiendo actuación del poder público a favor de esta cuestión de salud pública.

Palabras-Ilave: Salud Laboral, Ambiente de Trabajo, Tutela inhibitoria, Justicia del Trabajo

\section{Introdução}

Com a promulgação da Constituição da República Federativa do Brasil de 1988, a dignidade da pessoa humana e o respeito ao meio ambiente foram inseridos como fundamentos do Estado Democrático de Direito no primeiro artigo da Carta Política (1).

O Direito Ambiental do Trabalho foi inserido no artigo 196, que trata da saúde como direito de todos e estabelece o dever do Estado de garanti-lo por meio de políticas voltadas para a redução do risco de adoecimento, bem como pelo acesso universal e igualitário a ações e serviços para a promoção, prevenção e recuperação da saúde, 
incluindo-se aí o direito à saúde do trabalhador e proteção do meio ambiente do trabalho (2). Já o artigo 225 protege o direito de todos a um meio ambiente ecologicamente equilibrado, essencial à sadia qualidade de vida, atribuindo a todos, poder público e coletividade, o dever de preservar o meio ambiente equilibrado, tendo como norteadores do Direito Ambiental os princípios da prevenção, da educação e do poluidor-pagador (3).

$O$ arcabouço legal que trata da proteção legal ao meio ambiente de trabalho compreende a Constituição Federal; a Política Nacional do Meio Ambiente, instituída pela Lei ํo 6.938, de 31 de agosto de 1981; a Consolidação das Leis do Trabalho - CLT, alterada pela Lei o 6.514, de 22 de dezembro de 1977; a Portaria oㅡ 3.214, de 8 de junho de 1978, e as Normas Regulamentadoras - NR do Ministério do Trabalho e Emprego, entre outras (4).

E especificamente relacionado com o ambiente de trabalho, o artigo $7^{\circ}, \mathrm{XXII}$, da Carta Magna traz o direito do trabalhador à redução dos riscos ambientais inerentes ao trabalho, tratando da defesa da saúde do trabalhador, cabendo assim ao Poder Público atuação ativa nessa esfera jurídica (5).

Com base na análise sistemática dos artigos 196 e 200 da CF, depreende-se que a saúde do trabalhador e o direito ambiental não se tratam exclusivamente de direitos trabalhistas, incluindo-se no rol dos direitos sociais à saúde, devendo ser garantido mediante políticas públicas sociais e econômicas, integrando-os na estrutura do Sistema Único de Saúde, por meio das ações de vigilância sanitária e epidemiológica da saúde do trabalho e da proteção do meio ambiente de trabalho (2). Assim, na criação do Sistema Único de Saúde - SUS - por meio da Lei oㅜ 8.080, de 19 de setembro de 1990, a saúde do trabalhador foi incluída no campo de atuação desse sistema, assim como a proteção do meio ambiente de trabalho (4).

Com relação à legislação infraconstitucional, temos a Lei oㅜ 6.938, de 31 de agosto de 1981, que estabelece a Política Nacional do Meio Ambiente que, em que pese não incluir o ambiente de trabalho expressamente em seu texto, foi recepcionada pela atual Constituição, conforme leciona Norma Sueli Padilha, estando o meio ambiente de trabalho incluído nessa política preventiva (3).

A CLT também protege a saúde do trabalhador e o meio ambiente de trabalho, atribuindo à empresa a obrigação de sua preservação, por meio de seu art. 157, em que 
determina a responsabilização da empresa em 'cumprir e fazer cumprir as normas de segurança e medicina do trabalho'; aos empregados, por meio do art. 158, a observância de tais normas protetivas; às Delegacias Regionais do Trabalho, a fiscalização do cumprimento dessas normas e adoção de medidas necessárias para garantir a proteção ao ambiente de trabalho, além de imposição de penalidades pelo seu descumprimento (3).

Além disso, o artigo 154 da CLT estabelece a obrigatoriedade das empresas de, além de fielmente cumprir as normas previstas na legislação trabalhista, cumprir adicionalmente com as disposições incluídas em códigos de obras e legislação sanitária estabelecidas pelos estados e municípios (6).

Nas normas protetivas da saúde do trabalhador citadas na legislação trabalhista incluem-se as Normas Regulamentadoras do Ministério do Trabalho e Emprego, instituídas por meio da Portaria no 3.214/78, que regulamentam as disposições acerca de saúde, segurança do trabalho e higiene do ambiente de trabalho, dentre elas as que tratam de prevenção de acidentes, equipamentos de proteção individual, controle de saúde ocupacional, prevenção de riscos ambientais, ergonomia, condições sanitárias de ambiente de trabalho, entre outras (3).

No âmbito do Distrito Federal, a Lei no 5.321, de 6 de março de 2014, institui o Código de Saúde do Distrito Federal, estabelecendo por meio do artigo 3a a obrigatoriedade da instituição de ações e serviços de vigilância em saúde do trabalhador, visando à proteção e à promoção da saúde individual e coletiva e à qualidade de vida da população, incluindo a promoção e proteção da saúde e da segurança do trabalhador, bem como atenção integral à saúde do trabalhador. Ademais, nessa normativa são estabelecidas punições por infração sanitária, dentre elas 'deixar de promover medidas adequadas de proteção coletiva ou individual necessárias à preservação da segurança e da saúde do trabalhador' (7).

Em que pese a riqueza legislativa no campo dos direitos dos trabalhadores, explanada acima, especialmente no que diz respeito à saúde do trabalhador e ambiente de trabalho, e de ter sido a primeira vez na história brasileira que tais matérias recebem proteção constitucional, ainda é preciso, em razão dos níveis alarmantes das estatísticas de doenças e acidentes de trabalho (8), uma progressão na efetivação 
daquelas políticas. Em especial é preciso modificar o atual paradigma, segundo o qual é priorizada a prática indenizatória, por meio do pagamento de adicionais de insalubridade/periculosidade e de indenizações judiciais por dano material, moral e estético, para avançarmos efetivamente na prevenção da exposição ocupacional a riscos ocupacionais à saúde e segurança do trabalhador (3).

De acordo os dados da Organização Internacional do Trabalho - OIT, o Brasil ocupa o quarto lugar na estatística mundial de acidentes de trabalho fatais (8). No período de 2000 a 2011, a Previdência Social concedeu 2,7 milhões de benefícios decorrentes de doença e acidentes de trabalho, resultando numa despesa correspondente a quase 2 bilhões de reais nesse período (9). E ainda, de acordo com dados estatísticos elaborados conjuntamente pelo Ministério da Previdência Social e Ministério do Trabalho e Emprego, no ano de 2013, foram registrados no Distrito Federal 8.907 acidentes de trabalho e doenças ocupacionais (10).

Em face dessa realidade em que os acidentes e doenças ocupacionais tomam proporção de problema de saúde pública, no $20^{\circ}$ Congresso Mundial sobre Segurança e Saúde no Trabalho, ocorrido em agosto de 2014 na Alemanha, a OIT estipulou a meta de zero acidente de trabalho, definindo como prioridade para a redução desses índices o investimento em prevenção (8).

Com base na legislação acima descrita, cabe ao Poder Executivo, por meio das Vigilâncias em Saúde do Trabalhador, vinculadas ao SUS, e das Delegacias Regionais do Trabalho, vinculadas ao Ministério do Trabalho e Emprego, realizar a promoção à saúde do trabalhador, bem como atuação preventiva e repressiva no campo da segurança e saúde do trabalhador (3).

Por outro lado, o Poder Judiciário também tem uma parcela de atribuição na proteção do ambiente de trabalho na medida em que julga pleitos de adicional de insalubridade e periculosidade, de pedidos de reintegração no emprego e indenização material e moral por acidentes de trabalho e doenças ocupacionais, além de julgar ações coletivas que visam a prevenção de riscos ocupacionais. Bem como o Ministério Público, a quem cabe 'a defesa da ordem jurídica, do regime democrático de direito e dos interesses indisponíveis da sociedade', nos termos do art. 127 da CF, incluindo a 
tutela do meio ambiente de trabalho, da saúde e integridade física e psíquica dos trabalhadores, por meio de instrumentos coletivos como a Ação Civil Pública (3).

Dessa forma, nas ações coletivas que visam a proteção do ambiente de trabalho, cabe ao Poder Judiciário analisar a concessão de tutelas de urgência nas situações de risco grave e iminente, e aplicar multas para o cumprimento das determinações, com fundamento no dever de garantir um ambiente de trabalho saudável (11). Assim, cabe ao magistrado a prudência de priorizar os aspectos de saúde e segurança do trabalho em detrimento ao risco de prejuízo econômico pela suspensão, interdição de atividades econômicas ou embargo de obras, tendo em conta que a proteção à vida e integridade física deve se sobrepor aos aspectos econômicos. De acordo com Raimundo Simão de Melo (3), devem fundamentar as decisões judiciais, cujo objeto é a proteção do meio ambiente de trabalho e da saúde dos trabalhadores, os princípios da dignidade da pessoa humana, do valor social do trabalho, da precaução e prevenção da saúde dos trabalhadores, além do princípio do poluidor-pagador, adicionando-se os princípios do desenvolvimento sustentável, princípio da participação e princípio da ubiquidade (3).

Assim, por meio de Ação Civil Pública, busca-se o cumprimento de obrigações de fazer ou não fazer com relação ao cumprimento de normas trabalhistas, mediante multa ('astreints'), sendo possível o pedido de interdição de posto de trabalho que coloque em risco a saúde e vida dos trabalhadores, bem como condenação em danos morais coletivos pelos prejuízos causados ao meio ambiente de trabalho, os quais normalmente são destinados ao Fundo de Amparo ao Trabalhador, conforme leciona Raimundo Simão de Melo (12).

Com a promulgação da CF/88, atribuiu-se à Justiça do Trabalho o julgamento de dissídios individuais e coletivos entre trabalhadores e empregadores (13), correndo na Justiça Estadual o julgamento das poucas ações coletivas propostas pelo Ministério Público Estadual visando a adequação de ambiente de trabalho, com interposição de incidentes de conflito de competência entre a Justiça do Trabalho e Justiça Comum Estadual (3).

Em razão da controvérsia acerca da competência para o julgamento dessas ações, foi decidido pelo STF por meio do Recurso Extraordinário nำ206.220-1, em 1999, em Ação Civil Pública proposta pelo Ministério Público Estadual contra o Banco do Estado 
de Minas Gerais, a competência da Justiça do Trabalho em ações coletivas com objeto de medidas preventivas no ambiente de trabalho, caracterizando a responsabilidade do poder judiciário trabalhista no julgamento da tutela e proteção à saúde do trabalhador:

EMENTA: COMPETÊNCIA. AÇÃO CIVIL PÚBLICA. CONDIÇÕES DE TRABALHO. Tendo a Ação Civil Pública como causa de pedir disposições trabalhistas e pedidos voltados à preservação do meio ambiente de trabalho e, portanto, aos interesses dos empregados, a competência para julgá-la é da Justiça do Trabalho (14).

Seguindo esse entendimento, em 9 de dezembro de 2003, foi publicada a Súmula no 736 do STF, definindo a competência de Justiça do Trabalho para julgar ações que tenham como causa de pedir o descumprimento de normas trabalhistas relativas à segurança, higiene e saúde do trabalhador (3). Finalmente, em 30 de dezembro de 2004, foi aprovada a Emenda Constitucional № 45/04, denominada Reforma do Poder Judiciário, que ampliou a competência constitucional da Justiça do Trabalho (artigo 114) para apreciar as demandas decorrentes de toda espécie de relação de trabalho, não só relação de emprego, o que caracterizou também o aumento da competência legitimada do Ministério Público do Trabalho (3).

Com base nesse cenário, interessa, por meio da análise das sentenças judiciais proferidas, identificar e caracterizar: (i) os fundamentos jurídicos das Ações Civis Públicas impetradas pelo Ministério Público do Trabalho relacionadas à defesa da saúde do trabalhador ou ambiente de trabalho no âmbito das varas trabalhistas; (ii) as alterações promovidas pela EC 45/04 na atuação do MPT; e (iii) os resultados dessa nova política em relação à proteção à saúde dos trabalhadores e ao ambiente de trabalho.

\section{Metodologia}

Pesquisa qualiquantitativa de sentenças judiciais proferidas nas Ações Civis Públicas propostas pelo Ministério Público do Trabalho, no âmbito das Varas Trabalhistas da $10^{\text {a }}$ Região, que engloba a jurisdição do Distrito Federal e Tocantins, relacionadas à defesa da saúde do trabalhador ou ambiente de trabalho, no período de 2000 a 2014. 
A pesquisa deu-se por meio da coleta das sentenças no banco de dados secundários no sitio eletrônico do Tribunal Regional da 10ª Região, de acesso livre e gratuito, disponível na web no endereço www.trt10.jus.br.

Para selecionar as decisões judiciais de interesse à pesquisa foram utilizados os procedimentos de busca do próprio banco de dados e, como argumento de pesquisa, as expressões: 'ação civil pública' e 'ministério público do trabalho'.

O procedimento, no entanto, mostrou-se insatisfatório, identificando um grande número de documentos sem relação com o tema da pesquisa e obrigando à análise individual das 3.480 sentenças trazidas como resultado da busca. Desse total, foram excluídas as sentenças que não decorreram de Ação Civil Pública e aquelas que não foram propostas pelo Ministério Público do Trabalho, resultando em 633 sentenças, as quais foram objeto de estudo.

A análise incluiu a totalidade das sentenças proferidas nas Ações Civis Públicas propostas pelo MPT e que tinham por objeto a proteção da saúde do trabalhador ou do meio ambiente de trabalho.

Os dados coletados foram organizados em matrizes específicas, para análise do conteúdo das sentenças, segundo a atividade econômica da empresa demandada, o objeto da ação, as normas de saúde do trabalhador que fundamentaram a decisão judicial, o deferimento ou não do pedido de antecipação dos efeitos da tutela, e procedência ou não da ação, classificando-as ano a ano, considerando a data da propositura da ação.

\section{Resultados e discussão}

Foram localizadas 633 sentenças proferidas em Ações Civis Públicas impetradas pelo Ministério Público do Trabalho no período de 2000 a 2014, no âmbito das Varas Trabalhistas do Tribunal Regional do Trabalho da $10^{\underline{a}}$ Região, das quais 70 , correspondendo a $11,1 \%$, relacionadas com as condições de meio ambiente de trabalho e com a saúde do trabalhador (Tabela 1). 
Tabela 1 - Ações Civis Públicas propostas pelo Ministério Público do Trabalho (ACP/MPT): total de ações impetradas e quantidade e proporção (\%) daquelas que tratam de saúde do trabalhador e ambiente de trabalho, segundo o ano em que foram propostas. Tribunal Regional da 10ª Região, Varas Trabalhistas, Brasília, 2000-2014.

\begin{tabular}{c|c|c|c}
\hline \multirow{2}{*}{ Ano } & \multirow{2}{*}{$\begin{array}{c}\text { ACP/MPT } \\
\text { (No) }\end{array}$} & \multicolumn{2}{c}{$\begin{array}{c}\text { ACP/MPT com temática de saúde e } \\
\text { ambiente de trabalho }\end{array}$} \\
\cline { 3 - 4 } & 4 & No & $\%$ \\
2000 & 8 & - & - \\
2002 & 6 & - & - \\
2003 & 6 & - & - \\
2004 & 6 & - & - \\
2005 & 15 & - & - \\
2006 & 31 & - & 9,7 \\
2007 & 32 & 3 & 6,3 \\
2008 & 72 & 2 & 11,1 \\
2009 & 64 & 8 & 15,6 \\
2010 & 77 & 10 & 19,5 \\
2011 & 88 & 11 & 8,5 \\
2012 & 109 & 9 & 9,7 \\
2013 & 93 & 9 & 13,6 \\
\hline Total & 22 & 3 & 11,1 \\
\hline
\end{tabular}

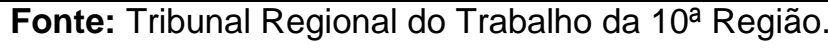

$\mathrm{Da}$ análise do quantitativo de sentenças organizado por ano, verificou-se um crescimento expressivo e sustentado do total de Ações Civis Públicas impetradas pelo Ministério Público do Trabalho junto às Varas do Trabalho vinculadas à $10^{\mathrm{a}}$ Região a partir do ano de 2005, e o início da propositura de Ações Civis Públicas com temática relacionada à tutela do meio ambiente de trabalho e à saúde do trabalhador em 2006, com tendência ao crescimento progressivo do número de ações, em que pese uma participação pouco expressiva dessa temática no conjunto total dessa modalidade de ação, variando da ausência de ações com essa temática no período de 2000 a 2005, a um pico de participação no ano de 2010, ocasião em que representou $19,5 \%$ das ações interpostas pelo MPT (Gráfico 1).

Essa ascendência iniciada no ano de 2005 coincidiu com a ampliação da atuação do Ministério Público do Trabalho em razão da instituição da Emenda Constitucional no 45/04, que, como explicado, ampliou a competência constitucional da Justiça do Trabalho, refletindo também no aumento da competência legitimada do Ministério 
Público do Trabalho, bem como a definição do conflito de competência entre a Justiça comum e a Justiça do trabalho, ocorrida em 2003, com a publicação da Súmula № 736 do STF, esclarecendo a competência de Justiça do Trabalho para julgar ações que tenham como causa de pedir o descumprimento de normas trabalhistas relativas à segurança, higiene e saúde do trabalhador (3).

Gráfico 1 - Total de Ações Civis Públicas propostas pelo Ministério Público do Trabalho (ACP/MPT) e ações que tratam de saúde do trabalhador e ambiente de trabalho, segundo $\mathrm{O}$ ano em que foram propostas. Tribunal Regional da $10^{\mathrm{a}}$ Região, Varas Trabalhistas, Brasília, 2000- 2014.

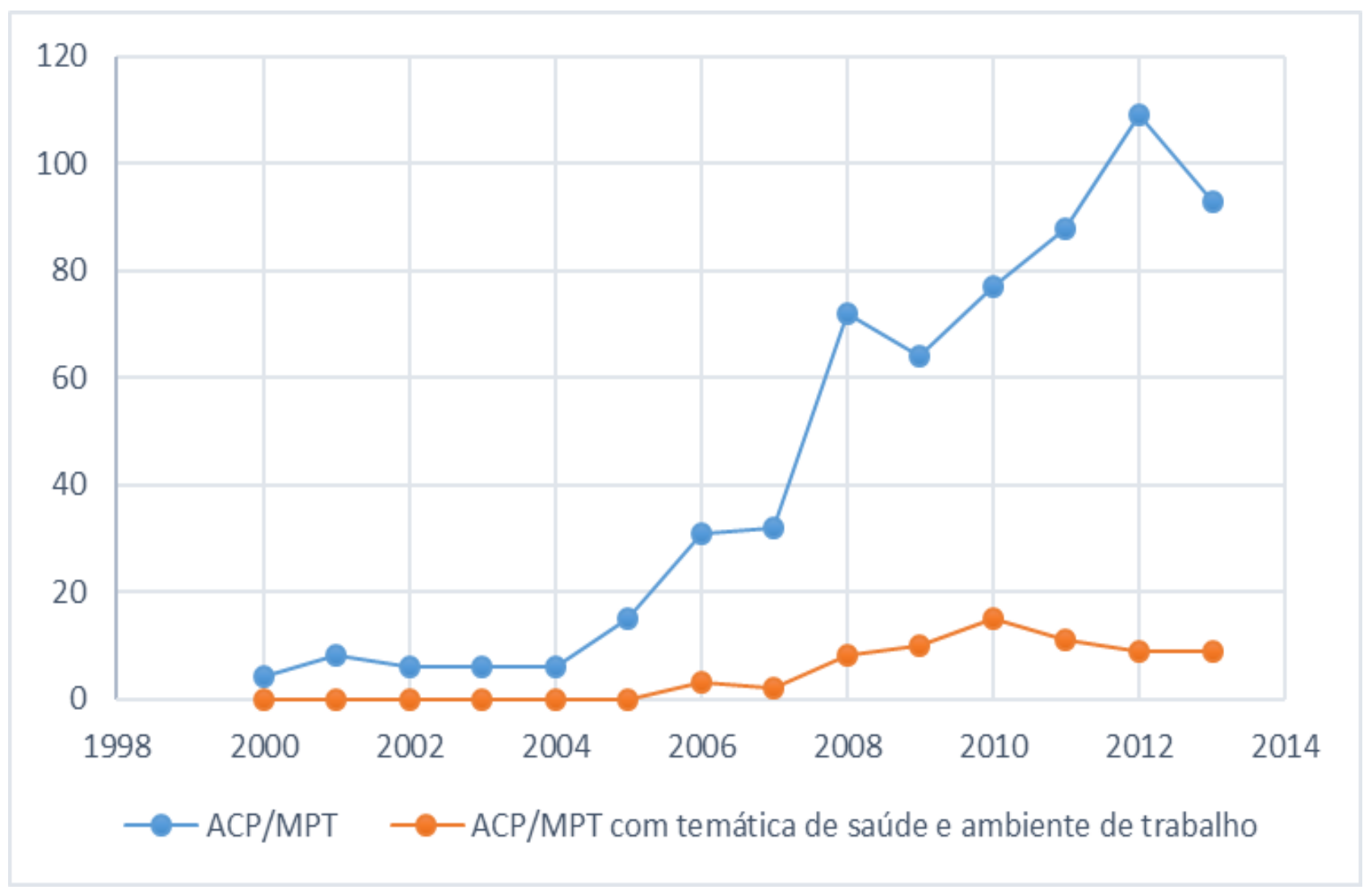

Fonte: Tribunal Regional do Trabalho da 10를 Região.

Feita a análise das características das Ações Civis Públicas propostas pelo Ministério Público do Trabalho no período de 2006 a 2014, constatou-se que a atividade econômica mais demandada no período fora a de construção civil e atividades relacionadas a ela, correspondendo a $20 \%$ das demandas, o que aponta para um comportamento reiterado de inobservância das normativas de segurança e saúde do 
trabalhador por empresas de construção civil; seguido pelas empresas de transporte urbano de passageiros, que participou com 11\% das ações do MPT (Tabela 2).

Tabela 2 - Ações Civis Públicas propostas pelo Ministério Público do Trabalho (ACP/MPT) que tratam de saúde do trabalhador e ambiente de trabalho, segundo a atividade econômica do réu. Tribunal Regional da 10 $10^{\text {a }}$ Região, Varas Trabalhistas, Brasília, 2006-2014.

\begin{tabular}{|c|c|c|}
\hline Atividade Econômica do réu & № & $\%$ \\
\hline Construção civil e atividades relacionadas & 14 & 20,0 \\
\hline Transporte urbano de passageiros & 8 & 11,4 \\
\hline Agropecuária & 6 & 8,6 \\
\hline Serviços & 5 & 7,1 \\
\hline Outras $^{1}$ & 5 & 7,1 \\
\hline Transporte aéreo e ferroviário & 4 & 5,7 \\
\hline Instituição bancária & 4 & 5,7 \\
\hline Transportadora de mercadorias & 4 & 5,7 \\
\hline Beneficiamento de frango & 3 & 4,3 \\
\hline Informática / Telemarketing & 3 & 4,3 \\
\hline Marmoraria & 3 & 4,3 \\
\hline Comércio varejista & 3 & 4,3 \\
\hline Vigilância patrimonial & 2 & 2,9 \\
\hline Posto de combustível & 2 & 2,9 \\
\hline Metalúrgica e máquinas & 2 & 2,9 \\
\hline Sindicato de empregados & 2 & 2,9 \\
\hline Total & 70 & 100,0 \\
\hline
\end{tabular}

Fonte: Tribunal Regional do Trabalho da 10를 Região.

${ }^{1}$ FIFA - Copa do Mundo do Brasil, Sebrae, energia elétrica, prefeitura, fábrica de bebidas

As demais empresas demandadas apresentaram as seguintes atividades econômicas: agropecuária; serviços; transporte aéreo e ferroviário; instituição bancária; empresa transportadora de mercadorias; beneficiamento de frango; informática e telemarketing; marmoraria; comércio varejista; vigilância patrimonial; posto de combustível; metalúrgica e máquinas; sindicato de empregados; FIFA - Copa do Mundo do Brasil, Sebrae, energia elétrica, prefeitura, fábrica de bebidas.

Quanto ao objeto específico da irregularidade apontada nessas Ações Civis Públicas, predominaram os temas relacionados com extrapolação da jornada máxima de trabalho permitida pela legislação, inobservância dos intervalos intrajornada e interjornada, bem como período mínimo de descanso semanal remunerado, os quais estavam presentes em $27,1 \%$ das ações (Tabela 3 ). 
Tabela 3 - Ações Civis Públicas propostas pelo Ministério Público do Trabalho (ACP/MPT) que tratam de saúde do trabalhador e ambiente de trabalho, segundo o objeto da demanda. Tribunal Regional da 10ํㅡㄹ Região, Varas Trabalhistas, Brasília, 20062014

\begin{tabular}{l|c|c}
\multicolumn{1}{c|}{ Objeto da demanda } & № & $\%$ \\
\hline Excesso de jornada de trabalho, & 19 & 27,1 \\
desrespeito intervalos obrigatórios & 15 & 21,4 \\
Condições das instalações sanitárias e de alimentação & 13 & 18,6 \\
Segurança de equipamentos e máquinas & 13 & 18,6 \\
Exposição insalubre sem EPIs & 11 & 15,7 \\
Segurança em canteiros de obra & 9 & 12,9 \\
Ausência de PCMSO e PPRA & 8 & 11,4 \\
Ergonomia e conforto & 7 & 10,0 \\
Assédio moral & 5 & 7,1 \\
Exposição a ruído sem proteção, sem monitorização audiométrica & 5 & 7,1 \\
Trabalho infantil / Condições análogas à de escravo & 2 & 4,3 \\
Maquinário seco em marmoraria & 2,9 \\
Exposição de gestantes e menores de 18 anos a agrotóxicos & 2 & 2,9 \\
Normas coletivas afrontando direitos constitucionais da saúde dos & 1 & 1,4 \\
trabalhadores & & \\
Transporte irregular de trabalhador &
\end{tabular}

Fonte: Tribunal Regional do Trabalho da 10ª Região.

Em 21,4\% dos casos, as demandas tratam da inadequação das condições das instalações sanitárias e das condições de instalações para alimentação. A segurança de equipamentos e máquinas e a exposição insalubre sem equipamentos de proteção individuais constaram em $18,6 \%$ das ações, cada.

Os demais objetos assinalados como irregularidade nas condições de meio ambiente de trabalho e saúde do trabalhador foram: segurança em canteiros de obra; condições de ergonomia e conforto; assédio moral; exposição a ruído ocupacional acima dos limites permitidos pela legislação brasileira sem a devida proteção individual ou coletiva e sem monitorização dos níveis audiométricos dos trabalhadores como medida preventiva do surgimento e agravamento de perda auditiva induzida por ruído ocupacional; utilização de maquinário a seco em marmorarias, com exposição irregular dos trabalhadores a sílica decorrente do corte a seco de pedras; além de transporte irregular de trabalhadores, em desrespeito às regras de saúde e segurança ocupacional.

Considerando ainda que foram evidenciadas 113 infrações nas ações estudadas, verificou-se a frequência média de 1,6 infrações por Ação. 
Chamou à atenção a presença de registro de cinco ações demandando empresas que, em pleno século XXI, ainda se utilizam de trabalho infantil, expõem trabalhadores a condições análogas à de escravo, bem como duas ações com registro de exposição de gestantes e menores de 18 anos a agrotóxicos.

Também causou assombro o acionamento de sindicatos de empregados que firmaram Normas Coletivas com empregadores em afronta aos direitos constitucionais garantidos aos trabalhadores relacionados à saúde e segurança dos trabalhado, apontando que o próprio sindicato, que deveria atuar em defesa dos direitos e garantias constitucionais dos empregados, firmou acordo coletivo com empregadores renunciando a tais benefícios.

Quanto à análise das normas jurídicas que fundamentaram os pedidos feitos pelo MPT e fundamentaram as sentenças proferidas, demonstra-se, por um lado, a riqueza de normativas com que essas ações são fundamentadas e, por outro, densidade de transgressões cometidas pelas empresas demandadas no que tange às normativas relacionadas à saúde e segurança do trabalho, bem como o meio ambiente de trabalho (Tabela 4).

Verificou-se que foram enumeradas transgressões trabalhistas em praticamente a totalidade da legislação brasileira que trata do tema, com predomínio dos direitos fundamentais registrados na Constituição Federal e da Norma Regulamentadora do Ministério do Trabalho e Emprego $n^{\circ}$ 6, de 1978, que trata da obrigatoriedade do fornecimento e utilização de equipamento de proteção individual adequado para o risco ocupacional a que o trabalhador está exposto.

Assim, demonstra-se que a saúde do trabalhador encontra fundamento em todos os níveis hierárquicos do sistema normativo brasileiro, perpassando a Constituição Federal, Leis Federais, Portarias, Normas e Regulamentos, conferindo ampla gama de proteção ao meio ambiente de trabalho e à saúde do trabalhador.

Adicionalmente, nota-se que, além das normativas tradicionalmente estudadas no âmbito da saúde e segurança do trabalho e ambiente de trabalho, explanadas inicialmente, outras normas também têm relação com critérios que devem ser observados nessa temática, tal como se demonstra na tabela 4. 
No entanto, observou-se que não foram referenciadas nas decisões analisadas outras legislações do Direito Sanitário que também regulamentam a saúde do trabalhador, tal como a Lei no 5.321/14, que instituiu o Código de Saúde do Distrito Federal e estabelece punições por infração sanitária; apontando para normativas que também poderiam ser utilizadas nos fundamentos judiciais relacionados a esse tema.

Tabela 4 - Ações Civis Públicas propostas pelo Ministério Público do Trabalho (ACP/MPT) que tratam de saúde do trabalhador e ambiente de trabalho, segundo o fundamento jurídico apontado na decisão. Tribunal Regional da 10a Região, Varas Trabalhistas, Brasília, 2006-2014.

\begin{tabular}{|c|c|c|}
\hline Fundamento jurídico apontado na decisão & № & $\%$ \\
\hline $\begin{array}{l}\text { Constituição Federal (arts. } 1^{\circ}, 5^{\circ}, 6^{\circ}, 7^{\circ}, 8^{\circ}, 21,154,170,196 \text {, } \\
200,225 \text { ) }\end{array}$ & 22 & 31,4 \\
\hline $\begin{array}{l}\text { CLT (arts } 59,66,67,70,71,74,224,225,235 \text { - jornada de } \\
\text { trabalho) }\end{array}$ & 21 & 30,0 \\
\hline CLT (art 8ㅇ, 154, 157, 161, 455) & 8 & 11,4 \\
\hline CCB - art. 186 & 1 & 1,4 \\
\hline Lei no 605/49 (repouso semanal remunerado) & 2 & 2,9 \\
\hline Lei no 6.019/74 (trabalho temporário) & 1 & 1,4 \\
\hline Lei no 6.514/77 (infrações contra meio ambiente) & 1 & 1,4 \\
\hline Lei no 6.938/81 (Política Nacional de Meio Ambiente) & 3 & 4,3 \\
\hline Lei no 7.183/84 (profissão aeronauta) & 1 & 1,4 \\
\hline Lei $\mathrm{n}^{0} 7.347 / 85$ (ACP contra danos ao meio ambiente) & 2 & 2,9 \\
\hline Lei no 7.565/86 (Código Brasileira de Aeronáutica) & 1 & 1,4 \\
\hline Lei no $7.802 / 89$ (aqrotóxicos) & 1 & 1,4 \\
\hline Lei no 9.605/98 (sanções contra meio ambiente) & 1 & 1,4 \\
\hline Lei no $10.101 / 00$ (participação lucros de resultados) & 1 & 1,4 \\
\hline Lei no 12.305/10 (Política Nacional de Resíduos Sólidos) & 1 & 1,4 \\
\hline Lei no $12.619 / 12$ (profissão de motorista) & 1 & 1,4 \\
\hline Convenções OIT (155 e 161) & 3 & 4,3 \\
\hline NR-01 (Ordem de serviço) & 2 & 2,9 \\
\hline NR-04 (SESMT) & 2 & 2,9 \\
\hline NR-05 (CIPA) & 2 & 2,9 \\
\hline NR-06 (EPI) & 22 & 31,4 \\
\hline NR-07 (PCMSO) & 14 & 20,0 \\
\hline NR-08 (Edificações) & 1 & 1,4 \\
\hline NR-09 (PPRA) & 21 & 30,0 \\
\hline NR-10 (Eletricidade) & 7 & 10,0 \\
\hline NR-11 (Transporte materiais) & 2 & 2,9 \\
\hline NR-12 (Sequrança máquinas e equipamentos) & 4 & 5,7 \\
\hline NR-13 (Caldeiras) & 3 & 4,3 \\
\hline NR-15 (Insalubridade) & 6 & 8,6 \\
\hline NR-17 (Ergonomia) & 7 & 10,0 \\
\hline
\end{tabular}


NR-18 (PCMAT)

NR-20 (Combustíveis)

NR-23 (Proteção contra incêndio)

NR-24 (Condições sanitárias)

NR-25 (Resíduos industriais)

NR-31 (Segurança agropecuária)

NR-32 (Segurança estabelecimentos de saúde)

Portaria no 43/08 (sílica)

Portaria $n^{\circ}=3.214 / 78$ (aprova normas regulamentadoras)

$\mathrm{NHO}$ no 1 da Fundacentro (ruído)

Nota Técnica ํo 3 CBM DF (incêndio)

ABNT/NBR 12693 (incêndio)

OJ no 307, 342, 354 - TST (intervalos)

Súmula no 85 - TST (compensação de jornada)

Fonte: Tribunal Regional do Trabalho da $10^{\mathrm{a}}$ Região.

Com relação aos resultados da análise da decisão em sede de pedido de antecipação dos efeitos da tutela, restou deferida a antecipação em $50 \%$ da totalidade das ACP. Porém, excluindo-se as 22 ações em que não consta, na sentença, registro de pedido de tutela antecipada nem decisão nesse sentido, verifica-se que o deferimento da antecipação ocorreu em 72,9\% das ações, demonstrando a presença de fumaça do bom direito e perigo da demora da manutenção da situação fática do meio ambiente de trabalho e segurança e saúde do trabalhador descrita pelo MPT. Assim, somente em $27 \%$ das ações em que houve pedido de antecipação é que ocorreu o indeferimento da tutela antes do julgamento da lide (Tabela 5).

Tabela 5 - Ações Civis Públicas propostas pelo Ministério Público do Trabalho (ACP/MPT) que tratam de saúde do trabalhador e ambiente de trabalho, segundo a decisão em sede de pedido de antecipação dos efeitos da tutela. Tribunal Regional da 10를 Região, Varas Trabalhistas, Brasília, 2006-2014

\begin{tabular}{|c|c|c|}
\hline $\begin{array}{l}\text { Decisão em sede de pedido de antecipação dos efeitos da } \\
\text { tutela }\end{array}$ & № & $\%$ \\
\hline Deferida a antecipação & 35 & 50,0 \\
\hline Indeferida a antecipação & 13 & 18,6 \\
\hline Sem registro de pedido de tutela nem decisão interlocutória & 22 & 31,4 \\
\hline Total & 70 & 100,0 \\
\hline
\end{tabular}

Fonte: Tribunal Regional do Trabalho da 10 ${ }^{\mathrm{a}}$ Região. 
Quanto à decisão de mérito da demanda, verificou-se que somente $20 \%$ das ações propostas pelo MPT foram julgadas totalmente improcedentes, sendo que, somando-se as ações julgadas procedentes (45,7\%) com as que tiveram homologação de acordo judicial feito entre o MPT e a empresa demandada (22,9\%), obteve-se 68,6\%, demonstrando elevada taxa de êxito do MPT nas tutelas inibitórias relacionadas à saúde e segurança do trabalhador (Tabela 6).

Tabela 6 - Ações Civis Públicas propostas pelo Ministério Público do Trabalho (ACP/MPT) que tratam de saúde do trabalhador e ambiente de trabalho, segundo a decisão de $1^{\underline{a}}$ instância. Tribunal Regional da 10aㅡ Região, Varas Trabalhistas, Brasília, 2006-2014

\begin{tabular}{l|r|r}
\hline \multicolumn{1}{c|}{ Decisão de 1’a instância } & № & $\%$ \\
\hline Procedente & 32 & 45,7 \\
Acordo homologado & 16 & 22,9 \\
Improcedente $^{\prime}$ & 14 & 20,0 \\
Extinção sem resolução de mérito $^{1}$ & 5 & 7,1 \\
Outros $^{1}$ & 3 & 4,3 \\
\hline Total & 70 & 100,0 \\
\hline
\end{tabular}

Fonte: Tribunal Regional do Trabalho da $10^{\mathrm{a}}$ Região (TRT).

${ }_{1}^{1}$ Pendente de julgamento, Incompetência territorial, Arquivado pela ausência do autor à audiência

Porém, em que pese a repercussão positiva da aprovação da Reforma do Poder Judiciário (EC no 45/04), que favoreceu o crescimento expressivo e sustentado das Ações Civis Públicas propostas pelo MPT como verificado, notou-se que a curva estatística de registros de acidentes de trabalho e doenças ocupacionais publicadas pelo Ministério do Trabalho e Emprego em conjunto com o Ministério da Saúde, apresentou elevação sustentada nos anos de 2008, 2011, 2012 e 2013 no Distrito Federal, conforme Gráfico 2 (10).

Ressalta-se que não foram localizados dados disponíveis no sitio pesquisado para os anos anteriores a 2007, nem posteriores a 2013 (10). 
Gráfico 2 - Incidência de acidentes de trabalho e doenças ocupacionais no Distrito Federal. 2007-2013.

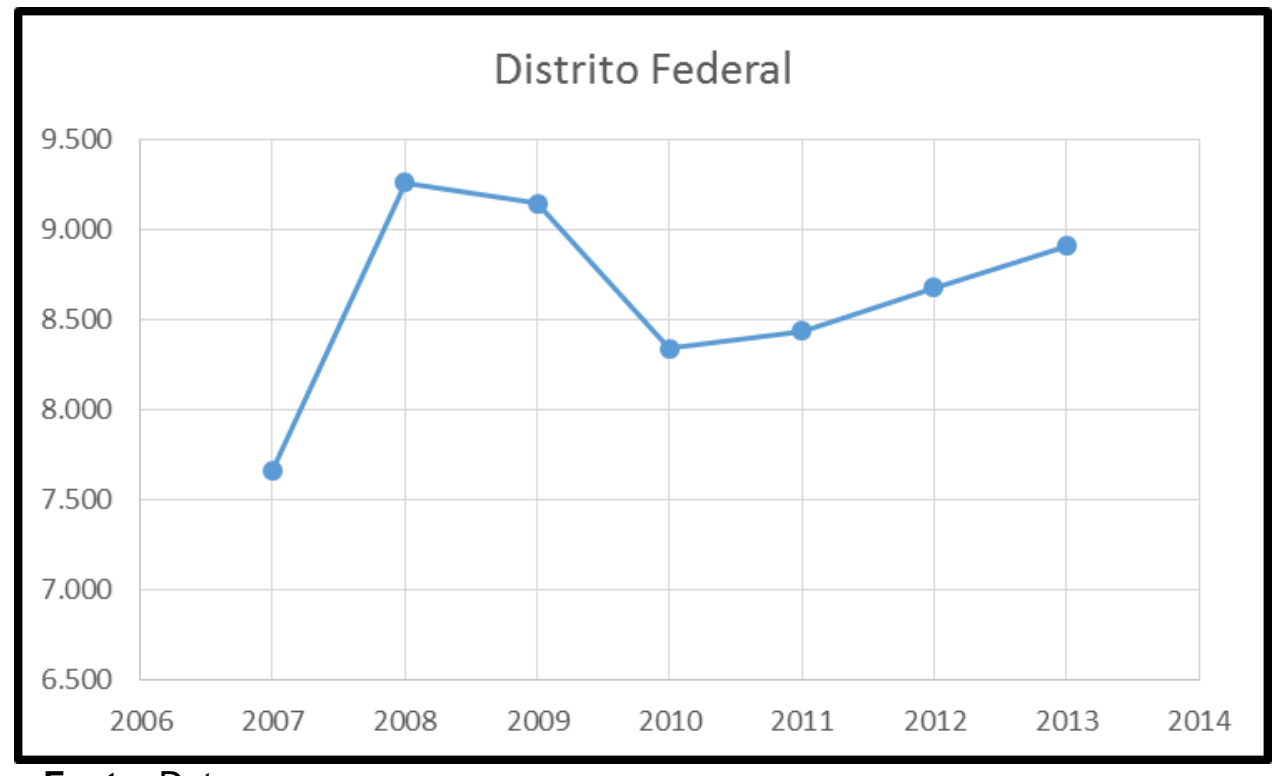

Fonte: Dataprev.

Assim, verifica-se que ainda é preciso fortalecer a atuação preventiva e repressiva dos órgãos públicos, incluindo o MPT, com objetivo de conscientizar empregadores e empregados acerca do cumprimento da legislação trabalhista, especialmente nos aspectos relacionados à saúde do trabalhador e ambiente de trabalho saudável, com objetivo de promover drástica redução desses índices de danos à saúde da população trabalhadora (15).

\section{Conclusão}

Observou-se que a Reforma do Judiciário representou marco na atuação do Ministério Público do Trabalho, por meio de tutelas inibitórias propostas contra empresas transgressoras da legislação trabalhista, tendo sua aprovação, em dezembro de 2004, sido seguida de crescimento expressivo e sustentado da quantidade de ações civis públicas a partir do ano de 2005; bem como das ações que tratavam de preservação ambiente de trabalho e saúde ocupacional a partir do ano de 2006.

O MPT se voltou especialmente às atividades econômicas de construção civil, transporte urbano de passageiros e agropecuária, que juntas representaram $40 \%$ das ações propostas no período de 2006 a 2014. 
Os principais objetos de descumprimento da legislação trataram de excesso de jornada de trabalho, desrespeito aos intervalos obrigatórios, condições das instalações sanitárias, segurança de equipamentos e máquinas e exposição insalubre sem equipamentos de proteção individual obrigatórios.

Ademais, notou-se a inobservância da quase totalidade das normas vigentes, 0 que demonstra que a riqueza normativa sobre a temática estudada não garante seu cumprimento com vista a um meio ambiente de trabalho saudável que preserve a saúde do trabalhador.

O MPT obteve elevados índices de sucesso nas suas demandas, no período estudado, com $72,9 \%$ dos pedidos de antecipação de tutela deferidos e $68,6 \%$ de êxito, considerando as decisões procedentes e os acordos homologados.

No entanto, apesar da intensificação sustentada da atuação do MPT junto ao Poder Judiciário após 2005, os índices de acidente de trabalho e doença ocupacional mantêm curva ascendente no Distrito Federal, demonstrando a necessidade da ampliação da atuação preventiva e repressiva de todos os órgãos responsáveis, incluindo o MPT, com objetivo promover redução desses índices de danos à saúde da população trabalhadora, que tomam a dimensão de problema de saúde pública. 


\section{Referências}

1. Brasil. Constituição (1988). [Internet]. [Acesso em 16 set. 2015]. Disponível em: http://www.planalto.gov.br/ccivil 03/Constituicao/Constituicao.htm.

2. Melo SN. Meio Ambiente do Trabalho: direito fundamental. São Paulo: LTr; 2001.

3. Melo RS. Direito Ambiental do Trabalho e a Saúde do Trabalhador. 4.ed. São Paulo: LTr; 2010.

4. Rossit LA. O Meio Ambiente de Trabalho no Direito Ambiental Brasileiro. São Paulo: LTr; 2001.

5. Silva OP. Direito à saúde do Trabalhador. Revista de Direito Sanitário, 2012, 12 (4): 81-85.

6. Padilha, NS. Do meio ambiente do trabalho equilibrado. São Paulo: LTr; 2002.

7. Brasil, Lei oㅜ 5.321, de 6 de março de 2014. Institui o Código de Saúde do Distrito Federal. [Acesso em 6 out. 2015]. Disponível em: http://legislacao.cl.df.gov.br/Legislacao/consultaTextoLeiParaNormaJuridicaNJUR290271!buscarTextoLeiParaNormaJuridicaNJUR.action

8. Organização Internacional do Trabalho. Doenças profissionais são principais causas de mortes no trabalho. OIT, 2013. [Acesso em 12 nov. 2015]. Disponível em: http://www.oit.org.br/content/doencas-profissionais-sao-principais-causas-de-mortes-notrabalho.

9. Brasil, Ministério da Previdência Social. Informe Especial por Ocasião do Dia Mundial em Homenagem às Vítimas de Acidente do Trabalho, 2014. MPS. [Acesso em 12 nov. 2015. Disponível em: http://www.previdencia.gov.br/wp-content/uploads/2014/04/lBoletim-Quadrimestral-de-Benef\%C3\%ADcios-por-Incapacidade1.pdf

10. Dataprev. Ministério da Previdência Social. Anuário Estatístico de Acidentes de Trabalho - AEAT, MTE, MPS, 2008-2013. http://www.previdencia.gov.br/dadosabertos/dados-abertos-sst/

11. Oliveira, SG. Proteção Jurídica à Saúde do Trabalhador. São Paulo: LTr; 2002.

12. Rocha, JCS. Direito Ambiental do Trabalho. São Paulo: LTr; 2002.

13. Ribeiro, INC. A ampliação da competência material da justiça do trabalho, sob o enfoque dos incisos i e ix do art. 114 da CF. Revista Âmbito Jurídico. Rio Grande, XVI, n. 115, ago 2013. [Acesso em 19 nov 2015]. Disponível em: http://ambitojuridico.com.br/site/?n_link=revista_artigos leitura\&artigo_id=13558\&revista_caderno=25. 
14. Brasil. Supremo Tribunal Federal. Recurso Extraordinário no 206.220-1. Recorrente: Banco do Estado de Minas Gerais S/A e outros. Recorrido: Ministério Público Estadual. Relator: Min. Marco Aurélio. Brasília, 16 mar. 1999. [Acesso em 18 nov. 2015]. Disponível em: http://redir.stf.jus.br/paginadorpub/paginador.jsp?docTP=AC\&doclD= $\underline{240376}$.

15. Ministério do Trabalho e Emprego. Estratégia Nacional para Redução dos Acidentes do Trabalho, 2015-2016. MTE, 2015. [Acesso em 12 nov. 2015]. Disponível em: http://acesso.mte.gov.br/data/files/FF8080814D5270F0014D71FF7438278E/Estrat\%C3 \%A9gia\%20Nacional\%20de\%20Redu\%C3\%A7\%C3\%A30\%20dos\%20Acidentes\%20do \%20Trabalho\%202015-2016.pdf. 